
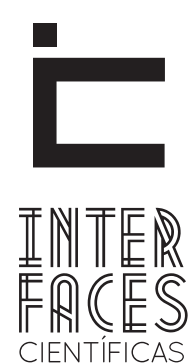

HUMANAS E SOCIAIS

\title{
EDUCAÇÃO SUPERIOR NO NORDESTE E QUALIFICAÇ̃̃O PARA O MERCADO DE TRABALHO
}

Ihanmarck Damasceno dos Santos ${ }^{1}$
Juliana Dias da Silva²

\section{RESUMO}

0 crescimento da economia e a expansão dos empregos gerados na primeira década do século XXI foram fundamentais para a valorização da educação superior pela sociedade brasileira, como estratégia de redução da desigualdade de renda e de mobilidade social. Este artigo faz um debate da relação entre a formação de capital social, o acesso a educação superior, a função social do ensino superior privado, qualificação para o trabalho, aumento da escolaridade da população e mercado de trabalho. A partir de uma análise quantitativa, exploratória e documental ten- ta-se apresentar o significado social das Instituições particulares o efeito gerado pelo aumento do acesso a educação superior na região Nordeste para alguns indicadores relacionados a desenvolvimento humano, renda e entrada no mercado de trabalho.

\section{PALAVRAS-CHAVE}

Educação Superior. Capital Social. Renda. Mercado de Trabalho. 


\section{ABSTRACT}

Economic growth and the expansion of jobs created in the first decade of this century were fundamental for the development of higher education by Brazilian society as a strategy to reduce income inequality and social mobility. This article is a discussion of the relationship between the formation of social capital, access to higher education, the social function of private higher education qualifications for the job, increase in schooling and the labor market. From a quantitative, exploratory and document analysis tries to present the social significance of private institutions the effect generated by increasing access to higher education in the Northeast for some indicators related to human development, income and entry into the labor market.

\section{KEYWORDS}

Higher Education. Social Capital. Income. Labor Market.

\section{RESUMEN}

El crecimiento económico y la expansión de puestos de trabajo creados en la primera década de este siglo fueron fundamentales para el desarrollo de la educación superior en la sociedad brasileña como una estrategia de reducción de la desigualdad de ingresos y la movilidad social. Este artículo es un análisis de la relación entre la formación de capital social, el acceso a la educación superior, la función social de las cualificaciones de educación superior privadas para el trabajo, aumento de la escolaridad y el mercado laboral. Desde una cuantitativa, análisis exploratorio y documento pretende dar a conocer la importancia social de las instituciones privadas, el efecto generado por el aumento del acceso a la educación superior en el noreste de algunos indicadores relacionados con el desarrollo humano, el ingreso y la entrada en el mercado laboral.

\section{PALABRAS CLAVE}

Educación Superior. El Capital Social. Renta. Mercado Laboral. 


\section{INTRODUÇ̄̃̃O}

A valorização da educação superior como estratégia de mobilidade social pode ser entendida como uma das marcas para os primeiros dez anos deste século. Caracterizado pelo crescimento da economia brasileira, pela expansão dos empregos gerados, redução da desigualdade de renda e expansão das matrículas na educação superior, o período de 2000 a 2009 possibilita uma abordagem e um debate contemporâneo sobre empregabilidade, aumento da renda, a formação de Capital Social e de outros benefícios associados ao aumento da escolaridade.

Como parte de uma pesquisa relacionada a educação, mercado de trabalho e desenvolvimento, este documento é motivado e tem como premissa a Teoria do Capital Social e a redução desta ao trabalho humano acumulado. A análise do impacto positivo da educação superior e alguns pressupostos.

\section{EDUCAÇ̃̃O SUPERIOR COMO QUALIFICAÇÃO PARA O TRABALHO}

A tendência de crescimento da população com mais de 15 anos de estudo na Região Nordeste tem acompanhado as diversas transformações que ocorreram no Brasil no intervalo de pouco mais de 20 anos. A maior preocupação com o tema, qualificação para o trabalho, e a democratização do acesso a educação superior acontece paralelamente a um cenário do domínio da hiperinflação e da promoção de importantes reformas para modernização econômica e institucional do País, final da década de 1990, e de avanços em importantes programas sociais durante a primeira década do século XXI.

Nos primeiros anos deste novo século, a expansão dos empregos e o crescimento do Produto Interno Bruto (PIB) brasileiro apresentam uma forte correlação. Entre 2001 e 2003, o aumento médio do PIB foi de $1,7 \%$, e o crescimento total do emprego formal foi de $12,6 \%$, o que significa uma expansão média anual de $4,2 \%$.

Já entre 2004 e 2008, período em que o PIB cresceu em média 4,7\%, o emprego formal aumentou $33,5 \%$, e o crescimento médio anual do emprego formal foi de 5,9\% (DIEESE, 2012). Segundo a Pesquisa Nacional de Amostras a Domicílio (PNAD) entre 2001 e 2009, a renda per capita média brasileira subiu $23,7 \%$ em termos reais, e a desigualdade de renda medida pelo índice Gini caiu entre todas as sucessivas PNADs do período (NERI, 2011, p. 14).

No Nordeste, o índice de Gini da distribuição de rendimento mensal para população economicamente ativa com 10 ou mais ano de idade alcança o pico em 2000 , quando marca 0,621 , enquanto no Brasil este coeficiente era de 0,609. Desde então, o índice apresenta uma curva descendente e cai para 0,578 em 2010, mas ainda superior ao observado para o País, 0,565 , segundo o censo demográfico do Instituto Brasileiro de Geografia e Estatística (IBGE) para os respectivos anos.

Para Barbosa Filho e Samuel Pêssoa (2009, p. 65), a educação teve papel central na redução da desigualdade. $20 \%$ a $40 \%$ da queda do índice Gini no período entre 2001 e 2005 pode ser explicada pela contribuição do mercado de trabalho, onde $2 / 3$ destes correspondem a redução dos prêmios pagos pela educação e $1 / 3$ à redução da desigualdade educacional. Para estes autores, os dois efeitos passam a contribuir na mesma direção, de maneira que se houver elevação da escolaridade, deve ocorrer elevação da renda per capita ou ainda do PIB per capita.

Partindo-se desta análise, a valorização da educação e do conhecimento como fonte de desenvolvimento, neste caso econômico, ganha espaço central na dis- 
cussão do investimento privado no País e na adoção de políticas públicas voltadas para formação de recursos humanos qualificados. Para Garcia (2003, p. 126),

[...] el conocimiento es visto como el mecanismo fundamental por medio del cual la empresa, la nación o la región adquieren su capacidad de generar, procesar y aplicar eficientemente la información que se transforma en conocimiento (knowledge). Así, se desplaza la idea de que una economía sólo puede generar riqueza mediante el capital físico, ya que ahora la base de cualquier economía es el capital intangible y el capital humano en su versión contemporánea del término.

Debates relacionados à necessária ampliação do acesso ao ensino superior em nosso País ganham destaque pela demanda crescente do mercado por profissionais com nível superior, a falta de mão de obra qualificada, no final da década de 1990 e início deste século, tendo como base de discussão o baixo percentual da população brasileira com mais de 15 anos de estudo.

Em 1996, a taxa de escolarização líquida no ensino superior da população, jovens entre 18 e 24 anos, era de apenas 6,2\% para o Brasil e de 3,4\% para a Região Nordeste (INEP, 2012). Percentuais muito abaixo da média de $30 \%$ dos países industrializados e até menor do que países vizinhos, a exemplo da Argentina que apresentava uma taxa de $22,4 \%$.

Fica evidente que o acesso educação superior brasileira era para poucos, caracterizando-se como um sistema elitista. Trow (1973) define e distribui os sistemas em três modelos:

[...] de elite, de massas e universal da seguinte forma: os sistemas de elite são aqueles que integram até $15 \%$ da coorte da idade em consideração - entre os 18 e os 24 anos; sistemas de massas são aqueles que integram entre $15 \%$ e $40 \%$ da coorte de idade; e sistemas universais aqueles que integram mais de $40 \%$ dessa população.

A importância e a correlação da educação na capacidade de geração de renda no mercado de trabalho estabelecem no Brasil uma forte ligação entre desigual- dade educacional e desigualdade de renda (LANGONI, 1974, p. 70). Nesta ótica, o entendimento do atraso educacional brasileiro, a percepção da educação superior como estratégia de mobilidade social e também de desenvolvimento das regiões brasileiras ganham força com o maior acesso ao ensino superior, tendo forte embasamento na teoria do capital humano ${ }^{3}$.

Com a globalização, a eclosão da sociedade da informação, o permanente desafio de elevação tecnológica, visando atender a necessidades do sistema produtivo, o aumento da escolaridade surge como a principal condição social para mobilidade daqueles que procuram emprego ou que já trabalham. A qualificação acaba funcionando como forca motriz para conquista e manutenção da empregabilidade, e dependendo da relação de forças até mesmo para conquista da liberdade. Para Ricardo Antunes (2004, p. 347), com as mudanças que vêm ocorrendo no mundo trabalho, a pressão por qualificação leva a perda de tempo livre da classe que precisa viver do trabalho:

[...] parte importante do tempo livre dos trabalhadores está constantemente voltada para adquirir empregabilidade, palavra fetiche que o capital usa para transferir aos trabalhadores as necessidades de sua qualificação, que anteriormente eram em grande parte realizadas pelo capital.

A busca constante de qualificação como inserção e permanência no mundo do trabalho, a crescente procura por educação superior, a procura de mais educação como direito social, a aspiração por mobilidade social por meio da educação universitária e a pressão do sistema produtivo por mão de obra cada vez mais qualificada, tornam latente que o déficit educacional no Brasil é um dos obstáculos, dentre outros, para o desenvolvimento econômico e social. A discussão sobre a estratégia de financiamento e acesso a edu-

3. No final dos anos 1950 e início dos anos 1960, estudiosos como Schultz, Becker e Mincer formularam a Teoria do Capital Humano. Para esses autores, a educação , do ponto de vista individual, deveria ser tratada como uma decisão de investimento. 0 indivíduo incorre em custos e aufere como benefício a elevação da renda propiciada pela maior escolaridade. Além disso, o ganho de renda individual experimentado pelo trabalhador em função de maior escolaridade representava a elevação de produtividade do trabalhador no local de trabalho (BARBOSA; PESSOA, 2009, p. 52). 
cação superior no País ganham agenda nos anos de 1996 e 2004, tendo como reflexo a implantação de políticas voltadas para expansão das matrículas em resposta às demandas da sociedade brasileira.

\section{DEMOCRATIZAÇ̃̃O DO ACESSO A EDUCAÇÃO SUPERIOR: BRASIL,NORDESTE E 0 AUMENTO DAS MATRÍCULAS}

Como resposta às políticas implementadas, o crescimento das matrículas na educação superior brasileira nos dez primeiros anos do século XXI foi expressivo. De acordo com os dados do Censo da Educação Superior do Instituto Nacional de Estudos e Pesquisas Educacionais Anísio Teixeira (INEP), de 2000 a 2009, o número de alunos matriculados no ensino superior cresceu $89,9 \%$, chegando a 5,12 milhões de matrículas. 0 fato relevante nesta discussão é o papel que coube a iniciativa privada como responsável pela ampliação das oportunidades de acesso ao ensino superior. Em 2009, 73,59\% dos alunos do ensino superior estavam matriculados em instituições privadas.

Destaca-se, também, o crescimento das matrículas do ensino superior no Nordeste, uma região pobre que apresenta uma herança histórica de desigualdade social e educacional, $28 \%$ da população brasileira e uma taxa de escolarização líquida no ensino superior muito pequena.

A expansão expressiva das matrículas na Região Nordeste é liderada pela iniciativa privada, que possuía no início da primeira década dos anos 2000, $34,3 \%$ de participação das matrículas na região, chegando a 2009 com $57,6 \%$ do total de matrículas. Com uma taxa anual média $14,63 \%$ de crescimento, bem acima da média brasileira nas áreas pública (4,3\%) e privada (7,61\%), o setor privado contribuiu, efetivamente, para ampliação do acesso da população nordestina a educação superior. Para referendar este argumento Figueiredo (2010, p. 16) afirma que "sem a iniciativa privada, o Brasil teria apenas 1,27 milhão de alunos matriculados no ensino superior".

As oportunidades de acesso a educação superior no Nordeste cresceram e a iniciativa privada foi fundamental para isto. Contudo, não foi o suficiente para alterar o quadro de desigualdade educacional quando comparada a outras regiões do País, no tocante ao percentual de matrículas, e as taxas de escolarização bruta e líquida.

Ainda vale destacar, para o período de 2001 a 2010, o incremento da participação da Região Nordeste nas matrículas, ultrapassando a região sul, mas ainda longe de resolver o problema quando comparados os percentuais de matrículas e populacional.

De maneira semelhante, a Região Nordeste chega a 2009 com a taxa de escolarização líquida semelhante a que o País possuía no início do século. Uma realidade complexa e demonstrativa de que só uma pequena parcela dos estudantes nordestinos tem conseguido chegar à educação superior, configurando ainda um sistema elitista. A Região Nordeste chega ao final da primeira década do século XXI com apenas $9,4 \%$ dos jovens de 18 a 24 anos, cursando o ensino universitário, de acordo com o IBGE/Pnad, elaborado por MEC/INEP.

Embora o País e a Região Nordeste, ainda, apresentem alguns dos piores indicadores dentre os países emergentes e regiões brasileiras, respectivamente, quando analisada as taxas de escolarização bruta e líquida no ensino superior, se faz necessário reconhecer que houve importantes progressos. Para isto foi fundamental a participação das instituições de educação superior privadas na oferta de vagas. A responsabilidade da iniciativa privada e complementaridade no sistema foram observadas por Serra (2010, p. 202) da seguinte forma:

Torna-se importante sublinhar que a reforma de 1968 preconizada para o ensino superior, e direcionada 
quase que exclusivamente as IFES, teve importantes consequências para o futuro do ensino superior, sendo a principal delas o aumento progressivo dos custos do ensino público, o que limitava a sua expansão e, ao mesmo tempo, proporcionava ao setor privado uma ocasião extremamente favorável para atender a crescente demanda que a União já não era mais capaz de absorver. Neste sentido, o ensino superior privado acabou por preencher uma lacuna no sistema nacional ao atender a progressiva demanda por formação superior [...].

A realidade que caracteriza a procura por educação superior não atendida na Região Nordeste pelas instituições públicas, reprimindo assim a demanda da população, torna-se evidente.

Embora as vagas e as matrículas no ensino superior público da região tenham crescido no período analisado, passando de 67.363 ingressos no ano de 2000 para 106.820 no final da década, um crescimento de $58,6 \%$, a ineficiência de atendimento a procura se manteve, podendo ser explicada pelo rápido exame de três fatos.

Primeiro, uma base e oferta de vagas muito pequena, reflexo de um modelo de educação superior que era voltado para atender apenas as elites. Segundo, a baixa capacidade orçamentária ou vontade política para o aumento do investimento pelo governo na educação superior pública, aliada a necessária priorização de aumento do investimento na educação básica.

De acordo com o MEC/INEP no Brasil a proporção do Investimento Público por estudante da Educação Superior sobre o Investimento Público por estudante da Educação Básica diminui ao longo do período de 2000 a 2009, explicada não pela redução do investimento no aluno da educação superior, mas muito mais pela manutenção do valor real investido neste e aumento do investimento no aluno da educação básica.

O terceiro fato está relacionado diretamente ao funcionamento predominantemente diurno característico das instituições públicas, motivo que conduz a exclusão e não atendimento dos estudantes que precisam trabalhar.

Instituições públicas montadas para poucos, a baixa capacidade de investimento do governo no setor e o alto custo do aluno da educação superior quando comparado com o aluno da educação básica, aliada a pressão da sociedade por maior acesso a educação neste nível, acabam reforçando a ideia da atuação necessária da iniciativa privada enquanto vetor complementar ao sistema.

Para Sampaio (2000, p. 20), a posição relevante do ensino superior privado no sistema, pela maior intensidade e velocidade que o setor público, foi construída por duas demandas que se complementam: a demanda da população por ensino superior até então extremamente reprimida e pela demanda do mercado de trabalho por pessoas com diploma de nível superior. Embora, o setor público também tenha crescido não se orientou necessariamente para o atendimento a demanda de massa, cabendo ao setor privado o desafio de ampliar as oportunidades de acesso a educação superior privada.

\section{SIGNIFICADO SOCIAL DA AMPLIAÇÃO DE OFERTA DE ACESSO A EDUCACÃO SUPERIOR}

O País passou por importantes mudanças sociais e econômicas na última década. 0 crescimento da renda, a superação de parte da população da linha da pobreza e a entrada de boa parcela numa classe com renda intermediária. Embora o sistema de ensino superior brasileiro possa ser classificado como elitista, observamos neste período a ampliação do acesso de estudantes das classes ${ }^{4}$ baixa (extremamente pobre, pobre mas não ex-

\footnotetext{
4. Utilizamos aqui a definição de classes desenvolvida pelo Grupo de Trabalho instituído pela Secretaria de Assuntos Estratégicos da Presidência da República (SAE/PR), por meio da Portaria Ministerial $n^{\circ} 61$, de 27 de setembro de 2011. Subdividiram a classe baixa em três grupos, a classe média em três grupos e a classe alta em dois grupos. A classe baixa em: i) os extremamente pobres, que são aqueles que possuem renda familiar per capita de até R\$ 81; ii) os pobres (mas não extremamente pobres), aqueles com renda familiar per capita entre R\$ 81 e R\$ 162 e iii) os vulneráveis, aqueles que estão acima da linha de pobreza e abaixo da linha da classe média, ou seja, que possuem renda familiar per capita
} 
tremamente pobre e vulnerável) e média baixa ao ensino superior, seja público ou privado.

De acordo com IBGE/PNAD, 2001-2009 na Região Nordeste a proporção de jovens 18 a 24 anos das classes baixa e média baixa cursando nível superior é maior que a média nacional. Esta proporção cresce nos sucessivos anos entre 2001 e 2009, chegando ao último ano a 22,3\% para região, contra 12,5\% no Brasil. A redução da desigualdade de acesso pode ser justificada pela maior oferta de vagas e política de cotas implantadas em universidades públicas, bem como pela entrada destes estudantes em instituições particulares por meio do programa universidade para todos (PROUNI).

Criado pelo Governo Federal em 2004, o PROUNI só foi regulamentado em 18 de julho de 2005 pelo Decreto $n^{0} 5.493$. Com funcionamento efetivo a partir do segundo semestre desse ano, o programa ofereceu entre 2005 e 2009 um total de 134.263 bolsas para estudantes da Região Nordeste, $15 \%$ do total de bolsas oferecidas para todo o País.

0 crescimento das matrículas em Instituições particulares para proporção de jovens de 18 a 24 anos das classes baixa e média baixa da Região Nordeste, é observado um aumento de 498,3\% entre 2001 e 2009, segundo IBGE/PNAD, chegando ao final da década com 63.250 estudantes, representando $47 \%$ do total de matrículas no ensino superior para o recorte em tela.

O significado social do setor privado pode ser demonstrado por dois caminhos que se correlacionam: o primeiro, por meio do acesso de jovens carentes a educação superior, inacessível pelos custos ou pela baixa oferta de vagas, enquanto estratégia de mobilidade positiva entre as classes. 0 segundo, motivado

entre R\$ 162 e R\$ 291. A classe média apresenta três cortes: a baixa classe média, que compreende aquelas famílias com renda per capita entre R\$ 291 e R\$ 441; a média classe média, que se encontra entre as faixas de renda de $\mathrm{R} \$ 441$ e $\mathrm{R} \$$ 641; por fim, a alta classe média, cuja renda familiar varia entre R\$ 641 e R\$ 1.019 per capita. Baixa classe alta, renda per capita menor que $\mathrm{R} \$ 2.480$ e alta classe alta com renda per capita maior que R\$ 2.480. Valores expressos em R\$ de abril de 2012. pela expansão das matrículas e crescimento das instituições, a partir da expressiva geração de empregos, docentes e técnico-administrativos, para atender a demanda dos estudantes pelo consumo de educação. Em 2009 as instituições de educação superior da Região Nordeste já eram responsáveis por 133.528 empregos, o que representa $12,5 \%$ do estoque de emprego formal na região.

As instituições de ensino superior da Região Nordeste, entre 2000 e 2009, geraram 30.206 empregos para funções técnico-administrativas no setor. No início da década, os empregos no setor público eram 4,6 vezes maiores que na área privada, relação está reduzida em 2009 para 1,2 vezes, demonstrando o potencial de geração de empregos pelo setor privado num intervalo de apenas 10 anos.

De maneira semelhante, observamos na iniciativa privada da Região Nordeste uma importante geração de empregos para funções docentes, de acordo com Ministério da Educação (MEC) - INEP em atendimento a demanda por mais educação superior. No período em estudo dos 39.108 empregos gerados para professores no ensino superior, $63,4 \%$ tiveram origem em instituições particulares.

\section{AUMENTO DA POPULAÇ̃O COM MAIS DE 15 ANOS DE ESTUDO E O MERCADO TRABALHO}

Como uma das rotas de entendimento dos desafios relacionados ao desenvolvimento do país e da região Nordeste é fundamental a interpretação do atraso brasileiro em termos educacionais como uma das variáveis de análise. Para Castro (1976, p. 3), “até mesmo as formulações mais inocentes postulam um nexo causal claro e inexorável entre educação e desenvolvimento econômico".

Entretanto, a evolução de indicadores econômicos não é condição suficiente para produção de um desenvolvimento mais inclusivo e ambientalmente su- 
portado. 0 Entendimento de que o acesso a educação superior como fomento ao desenvolvimento econômico, aumento da produtividade do indivíduo e, consequentemente, nos seus rendimentos dos indivíduos, tem como importante referência a teoria do capital humano. Um dos formuladores desta teoria Schultz (1973, p. 69) afirma que a educação é:

[...] predominantemente uma atividade de investimento realizado para o fim de aquisição de capacitações que oferece satisfações futuras ou que incremente rendimentos futuros da pessoa como agente produtivo, [...] proponho, por isso mesmo, tratar a educação como um investimento e tratar suas consequências como uma forma de capital.

O incremento da renda, enquanto consequência do aumento das credenciais educativas pode ser observado como apenas mais um, nem garantido e nem exclusivo, benefício. Para outros benefícios oriundos do fator educação, Fernandes e Gremaud (2009, p. 220) apontam que:

[...] além dos aspectos econômicos, a escolaridade tem sido associada, também, a uma variedade de benefícios não-econômicos: melhor saúde, redução da criminalidade, menor incidência de gravidez na adolescência, maior coesão social [...].

Relacionar o aumento da escolaridade como apenas o aumento de rendimentos ou desenvolvimento econômico não responde à complexidade de fatores culturais, sociais e políticos tão essenciais ao desenvolvimento local ou social. Carlos Milani (2003, p.1) afirma que "o crescimento econômico não produz, necessária e diretamente, o desenvolvimento social; [...] as instituições e o sistema social são elementos-chave na resolução do problema de acesso aos benefícios econômicos produzidos e de sua repartição".

De maneira complementar é preciso ter a noção de que acesso a educação, por sua vez, também, permite o ingresso a estruturas sociais, o aumento da sociabilidade, o acesso a informações sobre oportunidades, num contexto em que a participação ou engajamento em grupos pode gerar resultados positivos para o indivíduo e a comunidade, ideia central da Teoria do capital Social. Portes (2000, p. 134) destaca:

A originalidade e o poder heurístico da noção de capital social provêm de duas fontes: em primeiro lugar, o conceito incide sobre as consequências positivas da sociabilidade [...] em segundo lugar, enquadra essas consequências positivas numa discussão mais ampla acerca do capital, chamando a atenção para o fato de que as formas não monetárias podem ser fontes importantes de poder e influência, à semelhança do volume da carteira de ações ou da conta bancária.

As relações do capital social com outras formas de capital chegam a ser destacadas por outros autores como Colemam (1988), no que respeita ao papel do capital social a criação de capital humano; Bourdieu (1985) que destaca a possível transformação dos diversos tipos de capital e a redução, em último lugar, de todos estes tipos ao capital econômico, conceituado como trabalho humano acumulado.

Os dados relacionados ao número de alunos formados e a empregabilidade destes nos últimos anos permitem observar com a evolução do ensino superior no Brasil, dois resultados importantes. Primeiro, como um dos caminhos para formação do estoque de um capital de nosso País que não é tangível, o capital social, e redução da desigualdade de renda. Entre 2001 e 2009, observamos como aumento do acesso a informação sobre oportunidades, o engajamento em grupos e a formação de vínculos sociais, a conclusão do ensino superior de mais de 4,4 milhões de alunos brasileiros por meio das instituições particulares, o que representa $72,3 \%$ do total no período (MEC/INEP).

O segundo resultado está relacionado diretamente com o aumento do prêmio pago para aqueles que estão ingressaram no mercado de trabalho. A conclusão do ensino superior traz como vantagens não só o aumento da escolaridade, fator importante para o desenvolvimento humano, mas também um maior rendimento. 0 Gráfico 1 demonstra que para o intervalo de 2000 a 2009, prêmio pago para aqueles que 
possuíam nível superior no Nordeste foi pelo menos 2,5 vezes maior do que para quem possuía apenas o ensino médio.

Gráfico 1 - Rendimento médio real ${ }^{1}$ dos trabalhadores com ensino médio e superior completo - Brasil e

Nordeste - $2000-2009$

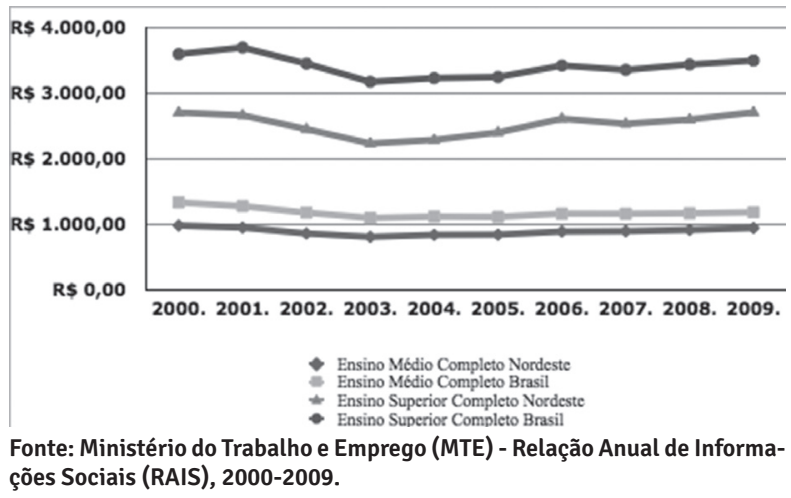

O Gráfico 1 ainda chama a atenção para o fato de que a Região Nordeste apresentou para o período analisado uma tendência de remuneração para os trabalhadores com ensino superior $25 \%$ menor que a média brasileira. Esta diferença pode ter como uma das explicações o excesso do lado oferta da força de trabalho com nível superior e baixa demanda pela força de trabalho associada à qualidade para este nível. 0 aumento concorrência na oferta do lado da força de trabalho pode e normalmente gera sacrifícios relacionados ao salário aceito.

Este argumento ganha força, considerando que ao todo foram formados nos dez primeiros anos do século XXI, 896.971 profissionais com nível superior na Região Nordeste. No mesmo período foram gerados em números absolutos 566.382 novos postos para trabalhadores que possuem 0 nível superior como grau de instrução (Ministério do Trabalho e Emprego (MTE) - Relação Anual de Informações Sociais (RAIS), 2000-2009. Dados sistematizados, 2014).
0 aumento da população com mais de 15 anos de estudo, a complementaridade entre a demanda do mercado de trabalho por mão de obra qualificada e a demanda da população por educação superior, mas com a concorrência do lado da oferta da força de trabalho bem maior do que o lado de demanda desta, caracterizando uma assimetria entre os dois lados do mercado.

Como consequência vamos observar na região um cenário com mão de obra qualificada abundante, em discordância com a fala da mídia nacional, e a existência de trabalhadores, que vão acabar sendo obrigados a aceitarem salários inferiores à média do País.

\section{CONSIDERACÕES FINAIS}

Avaliar os impactos do acesso ao ensino superior, em curto prazo, no tocante aos diversos benefícios gerados pela educação é um processo difícil e na maioria das vezes de extrema complexidade. O Nordeste como recorte espacial e a primeira década como recorte temporal, o artigo em tela buscou traçar para esta região que é pobre e que apresenta uma herança histórica de desigualdade social e educacional,o papel das instituições públicas e privadas, enquanto porta de acesso a oportunidades, ao mundo do trabalho, conquista de maiores rendimentos e de desenvolvimento social pelo incremento da escolaridade e de outros benefícios relacionados. Para tanto, foi utilizada uma abordagem quantitativa, tendo como suporte a Teoria do Capital Social e a redução desta dentre as diversas formas possíveis para o Capital Humano.

Como análise fundamental para condução e desenvolvimento de políticas públicas voltadas para 0 acesso a educação superior na região Nordeste, é importante observar uma evolução positiva no período, mas também a necessária inserção de mais jovens no sistema como estratégia de incremento da baixa taxa de escolarização líquida no ensino superior ao final década passada. 
Embora exista a correlação entre o aumento da escolaridade e o incremento da renda, preocupa este autor o baixo rendimento auferido pelos trabalhadores com mais de 15 anos de estudo da região Nordeste quando comparado a média brasileira. É importante destacar que neste estudo não avaliamos questões relacionadas a etnia, sexo e cor. Outro fator preocupante está relacionado a menor demanda do mercado pela força de trabalho com nível superior, quando comparado ao número de egressos das instituições universitárias, tendo como consequência a ausência de garantia de empregabilidade.

Neste contexto, ressaltamos que este texto é um resultado parcial de uma pesquisa ainda na fase inicial, mas que já procura não apenas aprofundar a discussão, mas que busca, também, desenvolver debates para que novas pesquisas se orientem para o tema em questão.

\section{REFERÊNCIAS}

ANTUNES, Ricardo; ALVES, Giovanni. As mutações no mundo do trabalho na era da mundialização do capital. Educ. Soc., Campinas, v.25, n.87, 2004. p.335-351.

BARBOSA FILHO, Fernando de Holanda; PESSÔA, Samuel. Educação, crescimento e Distribuição de Renda: a experiência brasileira em perspectiva histórica. In: BARBOSA FILHO, Fernando de Holanda; PESSÔA, Samuel. Educação Básica no Brasil: Construindo o país do futuro / organizadores, Fernando Veloso... [et al.]. Rio de Janeiro: Elsevier, 2009. p.51-72.

BOURDIEU, P; RICHARDSON, J. G. (Org.). The forms of capital. Handbook of Theory and Research for the Sociology of Education, Nova lorque, Greenwood, 1985, p.241-258.

BRASIL. Presidência da República. Comissão para definição da classe média no Brasil. Brasília -DF: Secretaria de Assuntos Estratégicos. Disponível em: <http://www.sae.gov.br/site/wp-content/uploads/ Relatório-Definição-da-Classe-Média-no-Brasil1. pdf>. Acesso em: 23 out. 2014.
CASTRO, Cláudio de Moura. Desenvolvimento econômico, educação e educabilidade. 2.ed. Rio de Janeiro: Tempo Brasileiro, 1976.

DIEESE. A Situação do trabalho no Brasil na primeira década dos anos 2000. Departamento Intersindical de Estatística e Estudos Socioeconômicos. São Paulo: DIEESE, 2012.

FERNANDES, Reynaldo; GREMAUD, Amaury Patrick. Qualidade da Educação: Avaliação, Indicadores e Metas. In: FERNANDES, Reynaldo; GREMAUD, Amaury Patrick. Educação Básica no Brasil: Construindo o país do futuro / organizadores, Fernando Veloso... [et al.]. Rio de Janeiro: Elsevier, 2009. p.213-238.

FIGUEIREDO, Hermes Ferreira. Uma Evolução consistente nas últimas três décadas. Produzindo Capital Humano: o papel do ensino superior privado como agente econômico e social / organizado por Klaus Kleber, Leonardo Trevisan. São Paulo: Cultura, 2010.

IBGE. Instituto Brasileiro de Geografia e Estatística. Síntese de Indicadores Sociais: uma análise das condições de vida da população brasileira 2010. Disponível em: <http://www.ibge.gov.br/home/estatistica/populacao/ condicaodevida/indicadoresminimos/sinteseindicsociais2010/SIS_2010.pdf> Acesso em: 25 nov. 2012

INEP. Censo da Educação Superior. Brasília: MEC/INEP 2012. Disponível em: <http://portal.inep.gov.br/web/ censo-da-educacao-superior>. Acesso em: 22 nov. 2012.

INEP. Resumo Técnico. Censo da Educação Superior 2010. Brasília: 2012. Disponível em: <http://download.inep.gov.br/educacao_superior/censo_superior/ resumo_tecnico/resumo_tecnico_censo_educacao_ superior_2010.pdf>. Acesso em: 15 nov. 2012.

INEP. Resumo Técnico. Censo da Educação Superior 2009. Brasília. Disponível em: <http://download.inep. gov.br/download/superior/censo/2009/resumo_tecnico2009.pdf>. Acesso em: 15 nov. 2012. 
LANGONI, Carlos Geraldo. As causas do crescimento econômico do Brasil. Ceará: APEC, 1974.

MILANI, Carlos. Teoria do Capital Social e Desenvolvimento Local: lições a partir da experiência de Pintadas (Bahia, Brasil). IV Conferência Regional ISTR-LAC; San José, Costa Rica, 2003. Disponível em: <http://www.lasociedadcivil.org/docs/ciberteca/carlosmilanip.pdf>. Acesso em: 20 abr. 2014.

NERI, Marcelo Cortês. Desigualdade de renda na década: FGV/CPS, 2011. Disponível em: <http://www. cps.fgv.br/cps/bd/DD/DD_Neri_Fgv_TextoFim3.pdf.>. Acesso em: 25 nov. 2012

PORTES, A. Capital Social: Origens e aplicações na Sociologia Contemporânea. Sociologias, Problemas e Práticas, n.33, 2000. p.133-158.

ROLIM, Cássio Frederico Camargo. SERRA, Mauricio Aguiar. Universidade e desenvolvimento regional: 0 apoio das instituições do ensino superior ao desenvolvimento regional. Curitiba: Juruá, 2010.

Recebido em: 30 de Março de 2015

Avaliado em: 6 de Abril de 2015

Aceito em: 9 de Abril de 2015
SAMPAIO, Helena Maria Sant'Ana. 0 ensino superior no Brasil: o setor privado. São Paulo: HUCITEC; FAPESP, 2000.

SCHULTZ, Theodore. 0 Capital humano. Rio de Janeiro: Zahar, 1973.

SERRA, Maurício Aguiar. O Sistema de Governança das Universidades. In: SERRA, Maurício Aguiar. Universidade e desenvolvimento regional: o apoio das instituições do ensino superior ao desenvolvimento regional. Rolim, Cássio Frederico Camargo. Curitiba: Juruá, 2010.

TROW, Martin. Problems in the transition from elite to mass higher education. Berkeley, CA. Carnegie Comissiono of Higher Education, 1973.
1.Doutorando do Programa de Pós-Graduação em Desenvolvimento Regional e Urbano - PPDRU/UNIFACS e Mestre em Química - UFBA. Superintendente de Relações Institucionais do Grupo Tiradentes. E-mail: ihanmarck@gmail.com

2. Doutoranda do Programa de Pós-Graduação em Educação da Unit. Mestre em Educação - Unit. Tem experiência na área de Matemática, com ênfase em Probabilidade e Estatística. Professora da Unit. E-mail: ju.aracaju@terra.com.br 
